\title{
MULHER, CORPO E VIDA: HISTÓRICO SOBRE O PARTO HUMANIZADO NA CIDADE DE CURITIBA
}

\author{
Carolina Damrat $^{1}$
}

- Enviado em 28/01/2016

- Aprovado em 15/02/2016

\begin{abstract}
RESUMO
Abordando a temática humanização do parto, o presente trabalho tem por objetivo auxiliar na divulgação de informações referentes à história do parto, modelos de parto e, principalmente, na conscientização sobre a prática do parto natural humanizado. Para sua elaboração fora utilizado autores como Paciornik (1987), Dutra (2005), Jones (2012), Davis-Floyd (2012) e Carneiro (2011), assim como relatos de mulheres expostos em web sites e redes sociais. Com a pesquisa é possível verificar a mudança de pensamento e de discurso que está acontecendo com as pessoas que entram em contato com o tema e aprofundam suas pesquisas. O parto natural humanizado é um tema em voga e que necessita de visibilidade e atenção.
\end{abstract}

Palavras-chave: Parto. Humanização. Mulher. Empoderamento. Ideologia.

\section{INTRODUÇÃO}

Este trabalho pretende abordar os aspectos históricos que constituem o desenvolvimento da prática do parto natural humanizado, utilizando como ponto de partida os estudos sobre parto de cócoras indígena realizados pelo médico obstetra Moysés Paciornik. O interesse pelo tema adveio de pesquisas informais sobre quais os cuidados necessários que a mulher precisa ter durante a gestação e o trabalho de parto. Em algumas destas pesquisas, apareceu uma "nova” concepção e prática de parto: o parto natural humanizado. A palavra 'nova' encontra-se entre aspas devido a sua contradição no contexto histórico da temática. Realizando uma pesquisa mais aprofundada sobre o assunto, o cenário encontrado demonstra que o incentivo pelo parto natural já possui uma longa história no contexto médico brasileiro, especialmente, curitibano. Assim sendo, a ideia principal deste trabalho é contribuir com a disseminação de informações pouco publicadas e debatidas no

\footnotetext{
${ }^{1}$ Pós-graduanda em História e Geografia do Paraná pela Faculdade ITECNE de Cascavel. Orientadora: Cida Grecco. Email: karol.damrat@gmail.com
} 
Paraná sobre o assunto 'partos', em especial sobre o parto natural humanizado. Estas informações fazem parte de uma série de questões e preocupações oriundas de uma fase específica da vida de uma mulher: a gestação de outra vida.

\section{PARTOS E PRÁTICAS}

Para se entender o parto e sua prática, é necessário primeiro compreender o sistema no qual ele se encontra inserido. Há cerca de três séculos, o parto deixou de ser um evento puramente feminino e passou por profunda modificação ao introduzir novos elementos como o médico, o hospital e os instrumentos cirúrgicos. Assim, a mística foi trocada pela medicina, a qual se divide em três modelos principais, explicados pela médica antropóloga Robbie Davis-Floyd no prefácio do livro Memórias de Um Homem de Vidro (2012), do obstetra gaúcho Ricardo Jones.

O primeiro modelo de medicina proposto é o Modelo Tecnocrático no qual se entende a separação entre mente e corpo, sendo este uma máquina e a pessoa um objeto, não havendo aproximação entre médico e paciente. Também se baseia na supervalorização da ciência e da tecnologia, sendo a morte encarada como uma perda. O segundo modelo é o Humanístico que pressupõe na unidade de mente e corpo, caracterizando este em um organismo e o paciente como um sujeito relacional. A ciência e a tecnologia são contrabalançadas com o humanismo, e a morte é um resultado aceitável. O terceiro e último modelo proposto por Davis-Floyd é o Modelo Holístico no qual se concebe mente, corpo e espírito como uma unidade energizada ligada com outros sistemas de energia. A ciência e a tecnologia são colocadas a disposição e a serviço do indivíduo enfermo e a morte é encarada como uma etapa de um processo no ciclo vida-morte.

A introdução do homem, o sexo masculino, no momento do trabalho de parto e na hora de parir fez com que a mulher parturiente se readequasse a esse novo elemento, pois esse homem representa duas situações extremamente opostas: o médico que pode violentar, inibir, transtornar, apoderar e conduzir o seu parto e suas ações e o marido/companheiro que pode acalentar, apoiar, transmitir segurança e conforto. Ambos não entendem o que a mulher está passando naquele exato momento, mas a postura que cada um toma faz com que estejam em lados opostos do mesmo acontecimento.

O ambiente em que o parto está sendo realizado também influencia muito no processo de trabalho de parto. Como consta na obra de Jones (2012) muitas das mulheres que passaram o 
período de trabalho de parto em casa, fazendo suas atividades cotidianas, se alimentando, se hidratando com água ou chás, tomando banho com duchas de água morna, mantendo a calma e se dirigindo à maternidade somente quando as contrações entraram em ritmo acelerado, não tiveram dificuldades para parir seus filhos de parto normal, isso quando elas não entravam em contato com o referido médico e ele se dirigia até a casa da parturiente para dar assistência, caso necessário, ao seu parto natural humanizado assistido também por outras mulheres como familiares, doulas e enfermeiras obstetras.

Porém, as mulheres que se dirigiam diretamente para o hospital nos primeiros momentos do trabalho de parto sofreram com as inseguranças do desconhecido, principalmente as mães de primeira viagem, ditas primíparas. Trata-se de uma situação desconhecida, com sentimentos e sensações desconhecidas, ambiente desconhecido e pessoas desconhecidas dizendo o que deve e o que não deve fazer, pensar, sentir. Em muitos relatos compilados no livro Memórias de um Homem de Vidro (2012) e de mulheres que expõem suas experiências nas redes sociais, se percebe que não houve e não há conforto, compaixão, simpatia, empatia transmitidos por parte do médico e de sua equipe. É apenas mais um parto para a equipe obstétrica, mas é o parto da vida do bebê de uma mulher.

Atualmente entendem-se três tipos de parto: a cesárea; o parto normal e o parto natural humanizado, os quais podem ocorrer em dois ambientes: no hospital ou na casa da parturiente. Há também diferentes posições, porém a mais comum e mais praticada é o decúbito dorsal, que consiste na posição em que a mulher fica deitada com a barriga para cima. A seguir uma breve definição sobre os tipos de parto e uma explicação sobre a posição mais usada na hora do parir e suas diferenças em relação ao parto de cócoras.

A cesariana é uma cirurgia na qual se abre o ventre e se retira o bebê. Indicado para casos como: quando a mãe apresenta deformações na bacia, ou desproporcional ao tamanho do bebê; quando ocorrem crises de oxigenação ao bebê durante o trabalho de parto; hipertensão ou diabetes. Vantagens: segurança, rapidez, simplicidade e comodidade que a cirurgia oferece à mãe e ao bebê. Desvantagens: a mulher perde o dobro de sangue, há maior risco de infecção, hemorragia e morbidade materna, recuperação mais demora e dolorosa, nos casos de intervenção eletiva, a criança pode nascer prematura e apresentar problemas respiratórios (DUTRA, 2005, p. 23) Segundo Paciornik:

A operação cesariana é uma das mais importantes aquisições da medicina de todos os tempos. [...] Seus riscos decorrem de suas qualidades. Médicos confiantes, confiados, alargaram suas indicações. Promoveram a ascensão da frequência. De $8 \%$ necessárias, de 
$16 \%$ toleráveis entre os mais cuidadosos - passa a 30, 40, 60, $80 \%$ entre muitos. (PACIORNIK. 1987, p. 61).

O parto normal é realizado via vaginal, em ambiente hospitalar, conduzido por uma equipe médica, geralmente na posição decúbito dorsal. Exposto a intervenções como episiotomia (abertura cirúrgica por meio de tesoura ou bisturi na vagina) e o uso de ocitocina sintética (reprodução sintética do hormônio "do amor" que ajuda acelerar as contrações uterinas), assim como instrumentos cirúrgicos como fórceps.

O parto natural humanizado é compreendido como a maneira mais natural de parir, com o mínimo de intervenções médicas e farmacológicas possível, respeitando o tempo da mãe e do bebê durante o processo do trabalho de parto. Pode ser realizado em casa ou no hospital, sendo que o ambiente escolhido tenha caráter respeitoso, acolhedor e confortável para a mãe. Todas as intervenções realizadas precisam do consentimento da parturiente, assim muitas escolhas podem surgir como o desejo de parir na água, de cócoras, em decúbito dorsal, tomar banhos relaxantes, realizar exercícios de yoga e demais procedimentos; médicos inclusive. (CARNEIRO, 2011 p. 13).

As posições usadas na hora do parto também são representações do modelo de medicina vigente no sistema cultural em que a mulher está inserida. Já vêm sendo usado por muitos anos a posição decúbito dorsal, mas poucos são aqueles que divulgam sua origem, o seu porquê e seus prós e contras. O obstetra Moysés Paciornik, referência principal neste trabalho, literalmente conta ao seu leitor de "Aprenda a Viver com os Índios" o 'nascimento' da posição. Segundo o obstetra curitibano, as mulheres sadias, com bom condicionamento físico, de modo geral, "com pequenas variações para terem seus filhos, se ninguém as pertuba com ensinamentos artificiais, assumem, automaticamente, a posição acocorada que, para elas, é lógica e, do ponto de vista médico, certa, fisiológica". Porém, com o desenvolver da sociedade humana, a diferenciação dos povos pela riqueza, tecnologia, indústrias, comodidade e sedentarismo, a mulher, muito pela falta de exercício, acabou por enfraquecer, sentindo grande dificuldade em se manter na posição primitiva de parir, necessitando assim de mecanismos que as auxiliassem como, por exemplo, as cadeiras de parto. Essas primeiras cadeiras de parto foram feitas especialmente para as grandes egípcias, 'grandes' por que eram obesas e não conseguiam, como as mal alimentadas e trabalhadoras camponesas, ficar de cócoras para ter bebê. 
Entre partos primitivos e partos especiais, o tempo passou e muitas crianças nasceram, muitas tecnologias foram criadas, muitos estudos iniciados e concluídos, mais comodidade para uma pequena parcela da população até chegarmos à França moderna com luxo, pompas, comida abundante para quem detém poder, tecidos caros e raros, muitas rendas, muitas golas, muito enfeite, muita roupa que fizeram com que nem a cadeira das obesas egípcias fosse adequada para as suas necessidades, como ilustra a imagem ao lado $^{2}$. Era muito baixa e difícil para a mãe e para o médico,

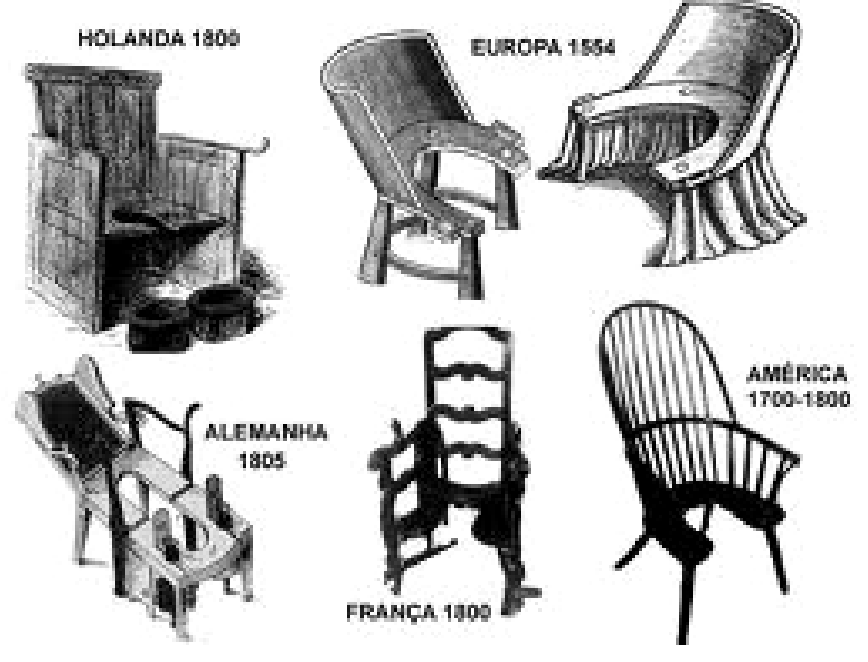
o melhor seria ficar alta e deitada em uma mesa, mais fácil para se apanhar as crianças recém-chegadas. Para a mãe, fraca e cansada, ficar deitada até que não era uma má ideia. Em pouco tempo a nova prática saiu da alta sociedade francesa e virou moda em outros países europeus, não precisando de muito mais tempo para chegar às classes mais baixas e se popularizar no mundo, tornando-se, pela visão de Paciornik, o maior fator de iatrogenia

(doenças causadas pelo médico, o médico como centro) da história da medicina:

$\mathrm{Na}$ verdade, o ato dos médicos, fazendo com que as mulheres se deitassem, foi uma consequência que, por sua vez, trouxe outras consequências, transformando-se, talvez, no maior fator de iatrogenia da história da medicina. Atingiu a mãe, atingiu o feto, o médico, e, por fim, a própria obstetrícia. (PACIORNIK, 1987, p. 19).

Entretanto, o que parece ser mais fácil e confortável é na verdade uma armadilha ardilosa. A posição decúbito dorsal intervém em uma série de mecanismos do corpo da mulher como no funcionamento do coração, o qual possui maior dificuldade para bombear o sangue causando palpitações. Nas mulheres deitadas, o útero repousa sobre os vasos retroperitonais, aorta e veia cava inferior. Quando o útero está grávido, a aorta consegue suportar esse sobrepeso, porém a veia cava inferior não. O resultado dessa demasiada pressão é o amassamento e diminuição do fluxo sanguíneo no terço inferior do tronco e membros inferiores, isto é, região que compreende o abdome e as pernas. Essa diminuição do fluxo sanguíneo pode causar a síndrome do colapso postural de mal-estar, cianose (coloração azulada nas mucosas e pele devido a pouca oxigenação do sangue), dispnéia (falta de ar), sensação de morte e, em casos mais graves, ao êxito letal (morte). As

\footnotetext{
${ }^{2}$ Imagem disponível em: www.nucleobemnascer.com. Acessado em 24 de novembro de 2015.
} 
complicações que o decúbito dorsal causa não afetam tão somente o funcionamento do organismo da mulher, mas também todo o processo de trabalho de parto: a dilatação, a expulsão e o secundamento (deslocamento da placenta).

$\mathrm{Na}$ dilatação o decúbito dorsal faz com que o processo fique mais demorado e sujeito a maiores complicações, pois grande parte da pressão que o peso da bolsa d'água e do próprio bebê exercem contra o colo, desvia-se para a parede posterior do útero sobre o qual repousam, como explica Paciornik. Isto é, em vez do peso auxiliar a abertura do canal vaginal, como acontece quando a mulher está na posição vertical, na horizontal esse peso é desviado de sua rota, sendo aplicado em uma região que não está preparada para recebê-lo e suportá-lo.

No processo de expulsão do bebê a posição deitada altera ainda mais o caminho do nascer. Quando de cócoras, o útero fica voltado para o chão e o peso da criança auxilia na sua busca pela saída, deslizando sua cabeça até o coroar, ou seja, quando a cabeça do bebê desponta na vulva. Nessa posição o cóccix também está livre, podendo se deslocar levemente para liberar um pouco mais de espaço se caso o canal vaginal se apresente um pouco estreito. As pernas e o abdômen também estão trabalhando e recebendo as quantidades ideais de sangue, pois o coração trabalha normalmente, garantindo oxigenação no cérebro, plena atividade dos pulmões e força nos membros inferiores. Quando deitada todo esse processo é invertido. Em vez de descer até coroar, a criança precisar subir, escalar o canal vaginal que está 'olhando' para cima, e o seu peso em vez de auxiliar em sua jornada, causa ainda mais dor na mãe que precisa fazer mais força para empurrar seu bebê até nascer, podendo causar graves lesões em seu assoalho pélvico. Nessa posição, o cóccix fica pressionado a uma superfície, imóvel, sem poder auxiliar na abertura do canal, o que pode resultar em escoriações e fissuras na vagina e vulva, incontinência de urina, gases e fezes, vagina frouxa e desajustes sexuais. As pernas, devido ao amassamento da veia cava inferior, não recebem as quantidades certas de sangue, ficando fracas, assim como seu grande potencial de sustentação é perdido, pois toda a força que a mulher faz para expulsar o bebê provem das coxas, músculos abdominais e torácicos, acaba-se exigindo demais de estruturas mal apoiadas.

Dessa etapa específica, a expulsão, muitas são as complicações que podem ocorrer para a mulher e para a criança. Na mãe geralmente acontecem: lesões de maiores proporções no assoalho pélvico (músculos que mantém o útero no seu devido lugar), comprometimento em estruturas como bexiga e uretra devido à longa exposição da jornada de escalar o bebê com força e repetidas vezes, fissuras e rupturas na vagina. Como forma de contornar a resistência do assoalho pélvico e agilizar o parto, algumas intervenções foram criadas como a episiotomia (abertura cirúrgica por meio de tesoura ou bisturi na vagina), sinfisiotomia (corte das fibras da sínfese púbica para permitir o 
aumento das dimensões pélvicas durante o parto), vácuo extrator (ventosa constituída por um semicírculo de metal ou silicone ligado a uma pequena bomba a vácuo, sendo ajustada mais atrás da cabeça do bebê), fórceps, cesárea, portadores todos de pesada carga de iatrogenia.

No bebê a demora e a força aplicada para sua subida aumenta as possibilidades de hemorragias intracranianas, causa principais da síndrome do sofrimento fetal (diminuição ou ausência da assimilação de oxigênio recebida pelo feto através da placenta), e lesões externas no crânio. Por também estar na posição horizontal, torna-se mais difícil para o feto livrar-se do conteúdo das vias aéreas, podendo causar estados de dispnéia (falta de ar), apnéia (interrupção da comunicação do ar atmosférico com as vias aéreas e pulmões), hipoxia (diminuição do aporte de oxigênio no corpo), anoxia (privação total de oxigenação no cérebro, podendo ter nome de sofrimento anóxico) e demais complicações. Esses danos podem ser percebidos logo após o nascimento devido ao seu caráter aparente, porém alguns podem passar despercebidos e causar problemas ao longo da vida da pessoa como disritmias, deficiência mental, paralisia espástica (rigidez muscular e dificuldade de movimento), coreoatetose (associação de movimentos involuntários contínuos, uniformes e lentos), ataxia (perda do controle muscular durante movimentos voluntários, como andar ou pegar objetos) e perturbações sensoriais.

Quando nascido o bebê, resta somente o deslocamento da placenta. O que deveria ser mais fácil e menos perigoso que o próprio parir, torna-se tão preocupante quanto se a mulher estivesse em decúbito dorsal. Segundo Paciornik, quando a mulher está na posição vertical o hematoma retroplacentar (bolsões de sangue atrás da placenta) e a própria massa placentária descem por seu peso até a abertura da vagina fazendo o caminho já trilhado e dilatado pelo bebê, conhecido como

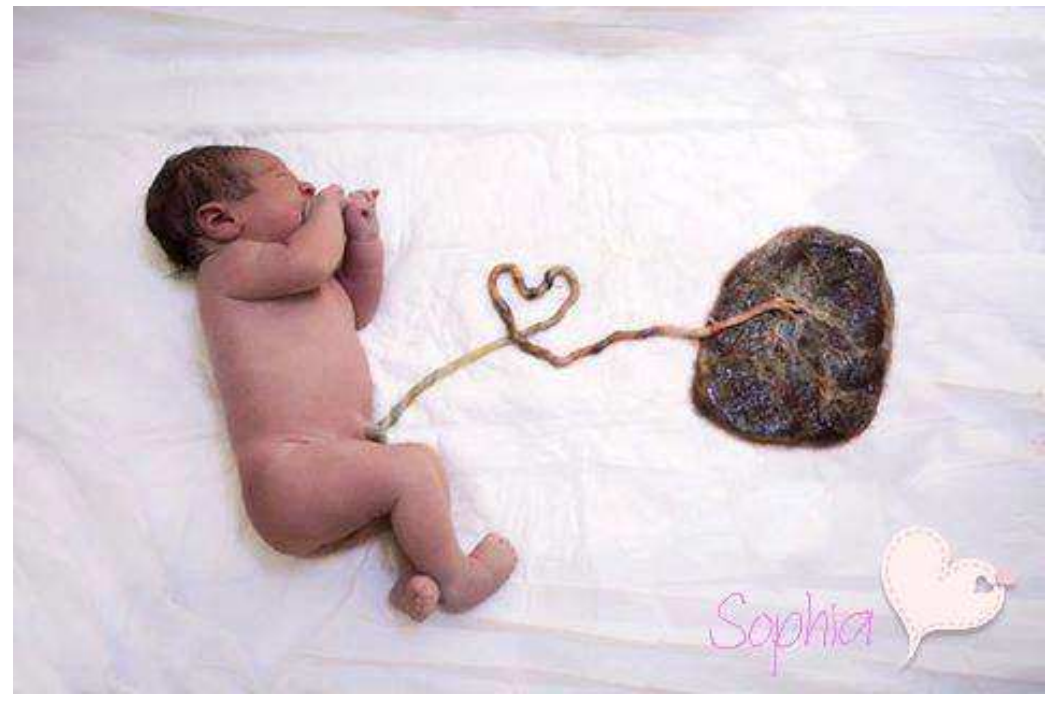
mecanismo de Shultze, saindo invertida parecendo um guarda-chuva, como ilustra a imagem ao $\operatorname{lado}^{3}$. Estando deitada, toda essa massa é jogada em direção errada, contra a parede uterina posterior, isso faz com que o hematoma placentar, levado pela tendência de deslocamento na direção de maior declive, force a passagem sob a borda placentar mais baixa,

\footnotetext{
${ }^{3}$ A história de Sophia e de sua mãe Taís Alves consta nos Relatos On-line, ao final do trabalho. Imagem disponível em: https://www.facebook.com/orenascimentodoparto/photos. Acessado a 25 de novembro de 2015.
} 
liberando-se em jato antes mesmo da saída da placenta, a qual acontece por escorregamento, fator que aumenta a perda de sangue e aumenta os riscos de complicações como hemorragias e infecções.

A hemorragia nessa fase do trabalho de parto é tão grave que pode inclusive levar a mulher à óbito. Geralmente ocorre devido à demora na expulsão da placenta que, retida no útero, impede a progressão do mecanismo de fechamento dos vasos miometrais que só se completa quando nada impede a contração uterina. Para acelerar o processo o médico executa uma variedade de manobras como massageamento, compressão, tração, torção que podem lesar fibras uterinas assim como fragmentar a placenta, que é expulsa incompleta, podendo gerar ainda mais hemorragias.

A infecção, por sua vez, pode ser causada através de ações dos próprios médicos impacientes pela demora do organismo da mãe para a expulsão total dos fragmentos, assim muitos invadem o canal vaginal e a cavidade uterina seja com instrumentos ou com a própria mão e braço, levando para dentro do organismo da mulher bactérias do ambiente. Além desse fato, dois outros acontecimentos podem desencadear graves infecções. Um deles ainda é referente aos fragmentos de placenta: caso o útero não esteja bem limpo, esses restos placentares com o passar dos dias ficarão desnutridos e constituirão um meio adequado para uma colonização microbiana. $\mathrm{O}$ outro é referente ao que pode ser introduzido no canal vaginal no momento em que o médico invade o organismo: além das bactérias pode-se ainda, dependendo de como ocorreu o momento de expulsão do bebê, ser introduzidos urina e fezes, causando grande infecção na mãe.

Foi analisando esses e outros fatores de sofrimento das mães e dos bebês que muitos estudos foram desenvolvidos a fim de mudar o quadro existente. Vários médicos, enfermeiras, doulas, parteiras, antropólogos e, principalmente, mulheres decidiram por transformar o conceito do nascer moderno e se voltar às verdadeiras necessidades e fatores do nascer humano que são o amor, a força, a presença, a dor e o êxtase da vitória. Entre estes estudiosos e defensores do parto natural está o médico ginecologista e obstetra Moysés Paciornik, que realizou entre mulheres urbanas e indígenas um verdadeiro trabalho de recuperação do nascer primitivo e humano.

\section{PACIORNIK, PARTO DE CÓCORAS E HUMANIZAÇÃO DO PARTO}

Ao se debruçar em suas observações sobre as posições de parir, Moysés Paciornik inicia um caminho de experiências e demonstrações sobre partos entre mulheres ditas civilizadas e as mulheres indígenas dos estados do Paraná e Santa Catarina, da etnia Kainguangue. Nascido em Curitiba em 1914, Moysés Goldstein Paciornik foi médico ginecologista e obstetra, graduando-se 
pela Faculdade de Medicina da Universidade Federal do Paraná (UFPR) no ano de 1938. Durante sua formação continuada, fez cursos de extensão universitária nas áreas de pediatria, doenças vasculares e periféricas, doenças do recém-nascido, patologias, psicologia e cardiologia. Atuou como médico cirurgião no Hospital da Criança de Curitiba; foi delegado da Associação Médica do Paraná e vice-presidente da Sociedade de Obstetrícia e Ginecologia do Paraná, assim como professor de Obstetrícia na UFPR. Em 1952 fundou a cadeira de Higiene Pré-Natal na mesma universidade.

No ano de 1959 fundou o Centro Paranaense de Pesquisas Médicas, do qual foi diretor. O centro dedicou-se à prevenção do câncer ginecológico e em serviços às reservas indígenas no sul do Brasil, predominantemente nos estados do Paraná e Santa Catarina. Foi nestas atividades que Paciornik tornou-se defensor do parto de cócoras, pois em suas observações constatou que as índias da etnia kaingangue, mesmo tendo muitos filhos (grande-multíparas) possuíam uma musculatura do assoalho pélvico mais firme que as demais mulheres que ele e sua equipe atendiam na cidade, as chamadas 'civilizadas'. Paciornik também foi um dos médicos precursores do exame Papanicolau no Brasil. A 26 de dezembro de 2008 Moysés Paciornik falece em São Paulo, aos 94 anos de idade, com 70 anos dedicados à medicina e a obstetrícia e 16 livros publicados.

Seus estudos sobre o que é e quais são as vantagens do parto natural de cócoras começaram a ser apresentados em congressos nacionais e internacionais já na década de 1970, como a Comparação entre eletroencefalogramas de indígenas nascidos de parto de cócoras e de outros indígenas e civilizados de parto em decúbito dorsal, estudo apresentado no Congresso Brasileiro de Ginecologia e Obstetrícia, Salvador, em novembro de 1978 e vencedor do Prêmio Menção Honrosa daquele ano. No ano seguinte, este mesmo estudo foi aprovado pelo Comitê Científico do Congresso Mundial de Ginecologia e Obstetrícia para ser apresentado em Tóquio, no mês de outubro. Segundo o autor, "a rigor, menos de dez por cento [das mulheres] necessitam da ajuda de uma parteira bem orientada e, destes, menos da metade necessitaria da colaboração de um médico mais experiente" (PACIORNIK,1987, pg. 14), ou seja, parir é tão natural, que a mulher sabe como preceder naturalmente na hora de ter seu filho.

Através de seu trabalho com as mulheres indígenas, o obstetra paranaense e seu irmão Cláudio Paciornik reuniram muitos dados e comprovações do quanto a cultura influencia o nascer. Sua primeira obra intitulada O Parto de Cócoras - Aprenda a Nascer com Os índios, publicada no ano de 1979, já trazia as diferenças entre o parir de cócoras e o parir deitada. No ano de 1987 foi lançado o livro Aprenda a Viver com Os Índios, obra que reúne não só a temática sobre o parto de cócoras, quanto temas como desempenho sexual, ginástica índia e alimentação saudável, 
disseminando práticas e hábitos indígenas que comparados aos hábitos modernos urbanos tornam-se ótimos caminhos para a volta do ser humano ao seu estado mais inocente e sensível, começando pelo seu nascer, pois Paciornik, já nos anos 1970, acreditava que se aprendêssemos a nascer com os índios mudaríamos a nossa visão de mundo.

No subtítulo de sua obra Influência sobre o relacionamento mãe-filho, o autor analisa o primeiro contato da mãe e de seu bebê logo após o nascimento. Quando a mãe está deitada, o desenvolvimento de seu parto ocorre longe de seus olhos, ela nada vê, só sente uma dor intensa e um medo imenso por não saber como está o nascer de seu filho. Quando o parto é de cócoras, imaginando agora uma mulher indígena, ela participa, vê, analisa e age no nascer de seu filho, que depois de coroar e nascer vai diretamente para o colo de sua mãe e o primeiro ato da indígena é dar de mamar para seu rebento, o acariciando e o amando. Como sabemos depois que nasce o bebê de decúbito dorsal, no hospital, na cidade, dificilmente o primeiro contato dele é realizado com a mãe. Primeiro o limpam, fazem as medições necessárias e só depois a mãe tem a oportunidade de conhecer o rosto de seu filho, e se o pai fora autorizado a entrar, a ele também.

Paciornik, ao defender o parto de cócoras, não faz alusão ao ser esse o procedimento perfeito que nunca trará malefícios a mãe ou ao bebê. Ele mostra, a partir de suas observações, os prós e os contras de parir na vertical assim como deixa claro que apesar do canal vaginal estar muito mais amplo e livre para a passagem da criança, podem ocorrer machucaduras na mãe como escoriações, leve rompimento do períneo, sangramentos, entre outros, porém em escalas muito menores ao se comparar os mesmos acontecimentos em decúbito dorsal.

O saber da dor, o conhecimento das possíveis complicações, o preparo físico e psicológico para se ter um bebê também fazem parte da humanização do parto. Aqui aproveito para contar duas passagens do livro Memórias de Um Homem de Vidro de Ricardo Jones (2012). Uma delas mostra o choque de um médico tecnocrata, o próprio Jones, ao se deparar com uma cena nunca vista e depois explicada pelo obstetra curitibano da maneira mais inacreditável possível. A segunda é sobre a integridade de uma mulher durante a gestação e o trabalho de parto.

Jones, por meio de seus relatos, deixa claro que passou por muitas transformações durante sua vida profissional até chegar a ser o médico humanista que é atualmente. O primeiro choque de realidade ocorreu depois de se deparar com um parto que aconteceu sem que ele fosse o condutor das ações durante o trabalho de parto; a mãe realizou o parto sozinha a seu tempo, de cócoras no chão de uma ala do hospital, ignorando a presença e as ordens impostas pelo homem ao seu lado. Isso fez com que Jones entendesse de forma ríspida que muitos dos partos que ele conduzira até então poderiam ter acontecidos de forma muito diferente, poderiam ter tido como protagonista não 
ele, o médico, mas sim a mulher. Após o acontecimento, Jones teve acesso à obra de Paciornik sobre o parir de cócoras.

Outro acontecimento que auxiliou no crescimento profissional e pessoal de Jones foi o caso Madalena. Madalena é uma mulher casada, vivendo em um lar simples, porém, muito acolhedor, e que fora mãe de cinco filhos. Todos seus partos foram no chuveiro de casa, pois Madalena, ao contrário da grande maioria das mulheres, não possui trabalho de parto. Após as primeiras e leves cólicas, seus filhos nascem. $\mathrm{O}$ encontro entre a paciente e o médico aconteceu por que ela precisou de um especialista junto a si logo após os nascimentos de seus filhos, a fim de evitar transtornos maiores por seus partos serem domiciliares. O que mais impressionou ao médico não fora o fato dos partos ocorrerem no banheiro de um apartamento, mas sim a facilidade com que aquela mulher, aquela família, aquele marido e aqueles filhos se integravam, uniam e recebiam o mais novo membro. $\mathrm{O}$ amor daqueles indivíduos para com a nova vida era de uma beleza tão extrema e pura que o médico pode entender que além das dores, dos medos, dos desconfortos e incertezas que um parto normal/natural pode sujeitar as pessoas envolvidas, há também muitos sentimentos bons, fortes e iluminados que fazem desse momento um momento de amor e poder.

\section{AÇÕES DE HUMANIZAÇÃO EM CURITIBA}

Atualmente em Curitiba o parto natural humanizado continua a ter seu espaço, mesmo que ainda restrito. A disseminação da temática e da prática tomou força em 2009 com a criação de grupos de apoio a gestantes e ao parto natural. Muitos congressistas e palestrantes renomados pisaram em solo curitibano e foram muito bem acolhidos pelas defensoras e defensores da prática. Existem grupos de doulas e enfermeiras obstetras que auxiliam nos partos naturais hospitalares ou domiciliares como o grupo Nascer com Respeito, organizado pela doula Patricia Bortolotto em parceria com o médico ginecologista e obstetra Dr. Carlos Miner Navarro e a equipe Yoga Funcional; como o grupo Doula Curitiba, o grupo Centro Parto Ativo, Mater Gaia, Casa Mãe, Movimento Bem Nascer Curitiba, Maternarum e Mãezíssima, assim como os cursos oferecidos pela Casa João de Barro. Todos estes grupos têm por objetivo apoiar e incentivar as mulheres que escolheram o parto natural humanizado em sua trajetória até depois do nascimento de seu bebê. Eles oferecem cursos de yoga, de alimentação saudável, rodas de conversas, contos e relatos (inclusive expondo alguns relatos em seus web sites), danças circulares para gestantes, cursos de massagem, cursos de cuidados dos primeiros meses de vida do bebê, e várias outras atividades que constroem laços entre a mãe, o pai e os filhos. 
No ano de 2010, o hospital Victor Ferreira do Amaral inaugurou novas alas com banheiras para a realização do parto na água acompanhado pela supervisão do Dr. Carlos Miner Navarro, um dos poucos médicos da cidade auxiliar partos na água. Assim como Navarro outros médicos curitibanos adentraram na humanização do parto como o Dr. Álvaro Silveira Neto e o obstetra Fernando Cesar de Oliveira Júnior. A prefeitura de Curitiba também está na missão de humanizar os partos atendidos pelo SUS. A maternidade de melhor índice de partos normais é a do Bairro Novo com 78\%, localizada no bairro do Sítio Cercado, seguida pela Victor Ferreira do Amaral com 72\%, depois Mater Dei e Hospital do Trabalhador com 66\%, Evangélico 55\% e por último o Hospital das Clínicas com $35 \%$. A Maternidade do Bairro Novo é a grande aposta da prefeitura para a humanização do parto. No ano de 2014 de março a meados de dezembro, a maternidade realizou 1.412 partos nos 42 leitos de alojamento conjunto, onde mãe e bebê ficam juntos. Atualmente, ela é responsável por uma média de 240 internações por mês, entre partos e outros procedimentos ginecológicos, além de cerca de 400 ecografias.

Entre as ações implantadas neste período para tornar o momento do parto mais humanizado está o uso do colete pele-a-pele, prática que aumenta o vínculo entre a mãe e o recém-nascido, permitindo a troca de calor, auxiliando na respiração do bebê e estimulando a amamentação; o banho humanizado é outra iniciativa para aumentar o conforto do bebê que fica em posição similar em que permaneceu no útero e isso o acalma e proporciona maior sensação de segurança; a visita dos irmãos mais velhos; o momento do conhecimento onde informações sobre o parto são ensinadas para as mães; massagens e relaxamentos; a escolha da posição do parir (se de decúbito dorsal, de cócoras, na água); a escolha de quem estará com ela durante o parto; assim como a presença do pai em todo o processo do nascimento do filho com a possibilidade de ele mesmo cortar o cordão umbilical. É uma maternidade que foi pensada para acolher da melhor forma possível e de possibilitar a mãe de se tornar a protagonista no nascimento de seu filho.

\section{RELATOS ON-LINE}

Neste espaço estão inseridos três relatos de mulheres que tiveram seus filhos de parto natural humanizado e compartilharam suas experiências em web sites e redes sociais. O primeiro relato é sobre o parto de Elena realizado pela dançarina e atriz Quitéria Chagas publicado pelo web site Ego, o segundo é sobre o parto de Sophia realizado por Taís Alves e publicado em uma página

\footnotetext{
${ }^{4}$ Dados do site: http://www.curitiba.pr.gov.br/noticias/indice-de-partos-normais-no-sus-de-curitiba-e-seis-vezes-maiorque-na-rede-particular/35110. Acessado a 15 de novembro de 2015.
} 
da rede social Facebook, e o terceiro é o relato do parto do Otto realizado por Vanessa Flasmo e publicado em seu blog particular.

\section{Relato $1^{5}$}

"Quitéria Chagas deu à luz sua primeira filha, Elena, no dia 11 de maio. A ex-rainha de bateria optou por fazer um parto humanizado, em uma banheira em sua própria casa, e, após cinco horas de trabalho de parto, a menina nasceu com 3.600kg e $52 \mathrm{~cm}$, às $19 \mathrm{~h} 10$. 'Ela nasceu de 40 semanas - quase princesa de Cambridge e estava limpinha, sem verniz, aquela massinha que protege a pele do bebê e ainda diz que ele está em preparação para nascer. Tinha duas voltas de circular de cordão, que muitos dizem enforcar o bebê, mas isso é um mito. O bebê não respira pelo nariz quando ligado ao cordão umbilical. Apesar da Elena ser grande, não tive nenhuma laceração, nenhum corte no períneo. Foi uma ótima recuperação! Pude caminhar, fazer minhas coisas. Bebês sabem nascer e mulheres sabem parir', defende Quitéria que, após engravidar, se tornou uma grande defensora dos partos normais.

Para ter a filha, a atriz contou com a ajuda de duas profissionais, a enfermeira obstétrica Marcella Pereira, que de tempo em tempo ouviu os batimentos cardíacos do bebê para ver se estava tudo bem, e a doula Gabriela Prado, que ajudou a aliviar as dores das cólicas de contrações. A própria Quitéria, aliás, se formou em doula durante a gestação. 'Essa foi a equipe, já que no parto humanizado elas só intervém quando necessário. Ninguém faz toque, perguntas ou atrapalha o processo que é completamente íntimo entre mãe, bebê e companheiro... A equipe fica em silêncio, só aguardando, e só quem entra na banheira sou eu e meu marido. Quando as pessoas me perguntam quem fez meu parto acho engraçado porque ninguém faz partos. Quem realiza tudo é a gestante com seu organismo e o bebê. Os reais protagonistas do parto natural não são obstetras, parteiras ou enfermeiras. São a mãe e o bebê e, se o pai estiver perto, ajuda bastante, já que os hormônios responsáveis pela expulsão do bebê são a ocitocina - o hormônio do amor - e a endorfina, os mesmo que são ativados no ato sexual. Infelizmente no Brasil só tratam como se fosse um ato puramente fisiológico, aumentando as complicações nos partos, riscos e mortes', fala.

Sobre a escolha de ter a filha na água, ela completou: 'A melhor coisa que fiz na minha vida foi ter parto em casa. No hospital eles diriam que minha bebê é grande e induziriam uma cesariana desnecessária, como ocorre tanto no Brasil. Tudo aconteceu na banheira porque queríamos que ela nascesse na água, já que diversos artigos científicos dizem que é menos impacto para o bebê, que nasce mais calmo. E realmente nossa bebê é bem tranquila. No hospital, o ambiente não é relaxante nem aconchegante e atrapalha e inibe o

\footnotetext{
5 O Parto de Elena. Publicado pelo web site EGO da Globo.com no dia 27 de Maio e escrito pela jornalista Luciana Tecídio. Disponível em: : //ego.globo.com/gravidez/noticia/2015/05/quiteria-chagas-da-luz-em-casa-e-defende-partohumanizado-radiantes.html. Acessado 15 de Novembro de 2015.
} 
trabalho de parto deixando a mulher mais estressada. Espero que meu relato encoraje e ajude as gestantes a realizarem partos naturais e diminuir o índice de cesáreas no Brasil como exige a OMS e o Ministério da Saúde. Realmente é o melhor para mãe e o bebê', acredita”.

O relato de Quitéria traz pontos muito interessantes para serem analisados. Durante a gestação, Quitéria se identificou com a proposta do parto natural humanizado e o escolheu como a alternativa preferível, inclusive participando de uma formação de doula. A escolha, as informações e o curso auxiliaram-na na construção de consciência e de discurso. Quitéria deixa claro em seu relato questões familiares para quem divide a mesma ideologia: o poder da mulher em parir (médicos não fazem partos), intervenções desnecessárias por parte da equipe médica (toques, introdução de ocitocina sintética, indução à cesariana, etc.) e pouco estímulo à prática de parto normal. Essas e outras questões são debatidas e analisadas pelos grupos que apoiam partos mais naturais e humanos e menos cartesianos e capitalizados.

Aqui, vale relembrar a divisão de medicina proposta por Robbie Davis-Floyd no prefácio do livro Memórias de Um Homem de Vidro (2012): medicina Tecnocrática, medicina Humanista e medicina Holística; e por essa divisão é fácil perceber que atualmente somos atendidos por um sistema tecnocrata e nascemos, na grande maioria das vezes, pelas mãos dele de forma padronizada, visando o seu conhecimento, o seu tempo e seu lucro e se esquecendo que é possível fazer de forma diferente. Quando a atriz diz: "Bebês sabem nascer e mulheres sabem parir", mostra o quão simples é a ideia: o nascer é um evento natural, um evento sentido pela mulher - Quitéria sabia que Elena era um bebê grande e que seria induzida a realizar uma cesariana para tê-la, mas não se deixou influenciar e confiou em seu corpo e na sua filha -, não necessita de grandes intervenções, de grandes investimentos financeiros, de grande capital girando em torno da temática. Na medicina tecnocrática, o parir, personificado na imagem da cirurgia cesariana, também é uma forma de produzir lucro, assim a padronização do evento extingue qualquer sinal de singularidade do momento, seja referente a parturiente e seu organismo, ao bebê e seu tempo, a participação de ambos no acontecimento.

Outro ponto da fala de Quitéria Chagas que merece atenção é quando fala “[...] no Brasil só tratam como se fosse ato puramente fisiológico, aumentando as complicações nos partos, riscos e mortes”, frase essa que acaba generalizando a temática 'partos'; assim como a própria Quitéria, existem muitas mulheres, mulheres gestantes, mulheres mães, mulheres ativistas, homens 'grávidos', homens pais, homens ativistas, grupos de conscientização, médicas, médicos, enfermeiras, enfermeiros, doulas, cientistas sociais e muitos outros que estão na luta contra o 
sistema tecnocrático de medicina e a favor do nascer natural e respeitado, lutando há anos como Moysés Paciornik que debatia o tema desde 1970.

\section{Relato $2^{6}$}

"Esta é Sophia, meu segundo bebê. A primeira gravidez foi uma cesariana eletiva. Eu sempre quis parir mas por falta de informação tive meu parto roubado. Quando fiquei grávida novamente, na primeira consulta com GO [ginecologista e obstetra] escutei que teria que ter meu parto antecipado em 36/37 semanas, pois eu tenho uma abdominoplastia e segundo as palavras dele... meu bebê não teria espaço pra crescer, eu sentiria muitas dores e que o fato de já ter uma cesariana teria que fazer outra. Eu não quis acreditar que eu passaria pela vida sem parir por culpa de escolhas minhas.

Fui em outra GO e escutei o mesmo. Foi aí desesperada por uma solução que assisti o trailer do Renascimento do Parto [filme sobre o tema] e comecei a pesquisar cada vez mais sobre os assuntos relacionados. Passei a gestação toda vivendo de parto. Eu ia parir ou pelo menos tentar e eu ia estar preparada pra lutar por isso. E assim foi! Sophia nasceu do dia 17/10/14 as 22h05. Em um parto domiciliar, eu tive meu VBAC. Foi um parto muito rápido com 40+6 [40 semanas e 6 dias], ela nasceu pesando 3,700kg e $52 \mathrm{~cm}$ para quem não teria espaço pra crescer, ela cresceu lindamente. Nasceu empelicada, foi recebida pelas mãos do papai e aos olhos do seu irmãozinho Matheus de 6 anos, que tanto pediu ela, em seguida veio para os meus braços e ali ficou e conheceu seu amado tetê, com mamoplastia redutora que muitas pessoas achavam que não sairia leite e que tanto saiu que hoje ela se alimenta 100\% e exclusivamente nele. Bebê que cresce em barriga com cesariana e abdominoplastia, sabe nascer no tempo dele. Eu sei parir! Seio com mamoplastia redutora dá muito leite sim!

Eu tinha tudo para ser impedida ou enganada novamente e não parir. Mas venci! Eu Pari e Amei!!! Sophia nasceu calando a todos que não acreditavam e provando para o sistema que o corpo e a natureza são perfeitos, mesmo que os médicos oportunistas digam que não."

$\mathrm{Na}$ fala de Taís Alves encontra-se pontos existentes também na fala de Quitéria Chagas: indução ao parto cesariana, desmotivação do parto normal, capitalização do nascer, mas há um ponto diferente. No relato de Taís há desmotivação e desrespeito à mulher gestante. Taís estava grávida de seu segundo filho (ao contrário de Quitéria que era primípara, mãe de primeira viagem e que teve a sua vontade atendida) e já havia sido induzida a realizar cesariana no primeiro parto, mesmo querendo tentar parto normal; em sua segunda gestação as restrições foram maiores devido

${ }^{6}$ O Parto de Sophia. Publicado pela página 'O Renascimento do Parto - O Filme' na rede social Facebook por Taís Alves. Publicação disponível em: https://www.facebook.com/orenascimentodoparto/photos. Acessado a 25 de novembro de 2015. 
ao seu histórico e ao pensamento "uma vez cesária, sempre cesária" o que acaba inibindo inclusive a vontade da mulher de tentar fazer diferente.

A ideia da capitalização do parto também é forte no relato de Taís. Quando ela diz: "Eu não quis acreditar que eu passaria pela vida sem parir por culpa de escolhas minhas" está trazendo à tona uma gama de situações que engendram o fazer dinheiro com o nascer. A culpa demonstrada por ela nesta frase está na criação de uma consciência que a escolha fora totalmente dela, sem ser induzida por ninguém, entretanto, ela deixa claro que a vontade de fazer parto normal a acompanhava desde a primeira gestação, ou seja, a escolha não foi dela, ela consentiu com uma ideia proposta, pois a sua fora ignorada. Após estudar sobre partos humanizados, Taís entendeu que o seu primeiro parto fora roubado de ti.

O sentimento de roubo geralmente é associado a bens materiais, porém o parto, mais que uma experiência memorável com valor sentimental por vezes negativo ou positivo, é também uma sifra, um valor monetário, assim podemos entender que o roubo sentido por Taís vai além do que ter um desejo desrespeitado, ela foi introduzida em um esquema que enxergava a ela e a Sophia, sua filha, como um valor a ser recebido e não seres com vida, com história, com vontades e sonhos.

Outro ponto que chama atenção no relato de Taís é a quantidade de adversidades que marcaram sua gestação e que mesmo assim foi possível realizar um parto natural humanizado em casa. Esse é um dos pontos que mais abre discussões sobre os riscos e perigos de parir sem intervenções médicas, mas com o exemplo do nascimento natural de Sophia e de tentas outras crianças que venceram as suas adversidades que se mostra ao mundo que o nascer é natural: cada parto é um parto, cada mulher possui seu poder de parir, cada caso é um caso, não há padrões e homogeneidade e é possível, mesmo com adversidades, realizar um parto humanizado, mais natural, mais respeitado, com mais ou menos auxílios e intervenções. Como Taís falou, "Sophia nasceu calando a todos que não acreditavam e provando para o sistema que o corpo e a natureza são perfeitos, mesmo que os médicos oportunistas digam que não."

\section{Relato $3^{7}$}

\footnotetext{
7 O Parto do Otto. Publicado pela curitibana Vanessa Flasmo no blog 'Enquanto vocês cresciam...' no dia 23 de Março de 2014. Publicação disponível em: http://enquantovocescresciam.blogspot.com.br/. Acessado 21 de Janeiro de 2016.
} 
"2h da manhã. Uma cólica. Fraca. Eu estava dormindo, acordei com o barulho do Julio se preparando pra dormir. Será? Sempre me falaram que quando fosse realmente a hora eu saberia, então se eu não tinha certeza, provavelmente não era. Volto a dormir. Outra cólica. Era a hora. Chegou o momento que eu esperei tanto. Mas vai demorar, claro. Vou tentar dormir. Mais uma. Como eu esperei sentir aquilo, difícil até de acreditar que o momento chegou. Preciso marcar o intervalo das contrações. Irregulares, bem espaçadas, dor muito suportável, vai demorar muito. Queria dormir, mas não conseguia. No auge de uma contração o Julio acorda e percebe que estou com dor.

"Tá tudo bem? Tá com dor?"

"Contrações, mas estão bem irregulares, pode dormir porque vai demorar."

"Mas, como assim? Já é contração de parto?"

"É, mas é só o começo, pode demorar muito. Não se preocupe que eu estou bem."

As dores foram ficando mais intensas, mais próximas, mas ainda sem ritmo. Fui pro banho. Tomei banho com a luz apagada, pra não despertar, queria voltar a dormir ainda. A água morna caindo na lombar aliviava toda a dor.

3h. Volto pra cama, sem roupa, enrolada na toalha. As dores agora vinham com mais força e com mais frequência, mas ainda sem ritmo.

"Ainda tá doendo?"

"Tá. Mas pode dormir, não vai acontecer nada antes de amanhecer"

Contração, contração, contração.

"Está vindo com mais frequência, né? Será q não é a hora de ir pra maternidade?"

"Não, não é assim, Julio. Só vou quando estiver insuportável."

[Eu queria ir pra maternidade o mais tarde possivel porque normalmente o trabalho de parto evolui melhor e é mais rápido em um ambiente em que a parturiente se sente segura. Com muitas mulheres o trabalho de parto acaba estacionando quando a mulher chega na maternidade. Aí, inevitavelmente, ela acaba sendo sujeita a intervenções médicas para acelerar o parto, o que aumenta a dor e também os riscos, especialmente pra quem, assim como eu, teve uma cesárea prévia.]

4h40. Escuto um "ploft", como se fosse uma bexiga estourando. Levanto rápido e instintivamente coloco a toalha no meio das pernas. Era a bolsa estourando. A toalha era branca, deu pra ver que a água estava escura. Meu obstetra havia me alertado a observar a cor da água, se a bolsa rompesse em casa. "Caso seja clara fique tranquila e observe as contrações. Caso seja escura, me ligue imediatamente.” Era escura. 
[A água fica escura pelo cocôzinho do bebê, o que pode indicar que ele está em sofrimento. Embora somente este fato não signifique nada isoladamente, é preciso avaliar outras coisas para afirmar, como o batimento cardíaco fetal]

"Julio, a água. A água esta escura."

"E agora? Vamos pro hospital!?"

"Calma, vamos ligar pro Dr. Alvaro."

“Não atende, Vanessa! Melhor a gente ir pro hospital!

[Nessa hora eu senti medo. Eu sabia que a água escura não era um bom sinal, meu bebê poderia estar em sofrimento, eu precisava fazer alguma coisa. Mas eu também sabia que chegar numa maternidade cesarista com bolsa rota, água escura, provavelmente sem dilatação e sem o meu obstetra... pfff... era cesárea de emergência mesmo que estivesse tudo bem com a gente! Mas ok, vamos. Eu realmente não contava com aquela água escura. Perdi o chão. Mas eu não poderia colocar meu bebê em risco. Dane-se o meu parto.]

As contrações ficaram muito fortes depois de romper a bolsa. Mal conseguia andar. Ajoelhava no chão. Uma contração atrás da outra, poucos segundos pra respirar. Desço e sigo em direção ao carro, parando a cada contração. A dor é bem forte, começa nas costas e irradia para o baixo ventre. Eu massageava a lombar numa tentativa em vão de aliviar um pouco. Totalmente em vão. Mas a dor não é constante, é como uma onda, começa leve e vai aumentando até o ponto que você pensa que não vai mais aguentar, ai ela começa a diminuir e some completamente. E você ganha alguns segundos pra respirar e se preparar pra próxima.

O trajeto até a maternidade é longo, uns $6 \mathrm{~km}$, mas nessa hora eu já não estava mais nesse plano. A dor intensa tira a racionalidade, leva a gente pra um estado de consciência diferente.

Chegando na maternidade o Julio foi fazer o internamento e eu de cócoras no meio do corredor tentando achar uma posição que aliviasse, em vão. Escutei alguém gritando chamando uma enfermeira. Me levaram pra sala de triagem. Aí começou a minha luta contra o falido sistema obstétrico tradicional brasileiro.

[O sistema tira da mulher o protagonismo do parto, tira da mulher a confiança no seu corpo, infantiliza a mulher a ponto de fazê-la acreditar que não é capaz de parir sem intervenção médica, que seu corpo é defeituoso. Um sistema que leva diariamente milhares de mulheres para uma grande cirurgia, desnecessariamente. A maioria destas mulheres queria parir, mas a série de erros e violências que ela sofre desde que dá entrada na maternidade a fazem ter certeza de que ela não é capaz. E pior, que foi "salva" pela cesárea. Eu não queria mais fazer parte dessa estatística.]

“Tá de quantas semanas?" 
“41”

"Bolsa rota?"

"Sim"

"Deita na maca que o obstetra já está vindo te avaliar"

"Não consigo deitar, prefiro ficar aqui. Me dá um copo d'agua?"

"Não pode tomar água, preciso que você deite pra ele te examinar"

"ok"

Chega o obstetra plantonista. Ouve o coraçãozinho do bebê, tudo bem. Faz o toque, sete centímetros.

"É teu primeiro filho?"

"Não, segundo"

"O primeiro foi parto ou cesárea?"

"Cesárea"

"E esse vai querer cesárea também?"

"Não"

"Ok, estamos tentando falar com o teu obstetra, enquanto isso vamos pro centro obstétrico"

"Eu preferia esperar meu médico chegar no quarto"

...risos da equipe plantonista...

"Não dá, mãezinha"

"senta na cadeira de roda pra eu levar você, mãezinha"

"eu prefiro ir andando"

"você não vai conseguir"

"eu não vou sentar, eu vou andando!!"

[Chamar a parturiente de "mãezinha" ao invés de chamá-la pelo nome, dizer o que ela não vai conseguir fazer, são exemplos de como se infantiliza uma mulher. Mulheres infantilizadas têm medo, se sentem incapazes. Não seria mais honesto encorajar a mulher neste momento?] 
O Julio foi fazer a papelada do internamento e eu fui pro Centro Obstétrico. Fomos direto pra sala de parto, que sinceramente deveria se chamar "sala de cirurgia" porque não é uma sala preparada para parto, absolutamente. É perfeita pra te operarem, não pra você parir.

A enfermeira me ofereceu analgesia, eu não quis. Pediu pra que eu deitasse que meu médico logo chegaria e saiu da sala. Não deitei, fiquei acocorada no chão, era a posição que me deixava mais confortável.

[A posição horizontal é a menos indicada para o parto normal, porque é contra a gravidade, além de aumentar muitíssimo a dor. O mais indicado é que a parturiente fique na posição que ela escolher. Só durante o trabalho de parto ela consegue saber como quer ficar. Ficar na posição que se sente mais confortável diminui drasticamente a chance de laceração.]

Entraram duas enfermeiras na sala conversando entre si, mexendo em agulhas, acessos, etc. Uma fala pra outra "eu trouxe o sorinho, será que ela vai querer, porque não quis nem analgesia..." Eu me meti na conversa dizendo que não queria. Elas saíram da sala.

[O "sorinho" é ocitocina sintética, usado para acelerar as contrações e fazer o trabalho de parto durar menos tempo. Quando se usa o sorinho a dor aumenta desumanamente, além de não ser indicado para quem tem uma cesárea prévia, já que faz o útero se contrair artificialmente, aumentando o risco de ruptura uterina devido a cicatriz da cesárea.]

Voltaram pedindo pra que eu deitasse na maca.

"Moça, deite na maca, pela posição que você está o teu bebe está quase nascendo, é melhor você deitar"

"Eu não consigo deitar, prefiro ficar assim!"

Continuo ali no chão, acocorada e sozinha. Peço pra chamarem meu marido.

"Calma, ainda não é a hora, quando estiver nascendo ele vem"

A enfermeira insiste que eu preciso deitar na maca, eu me nego.

"Se você não deitar na maca teu bebê vai nascer e cair de cabeça no chão, você quer isso?"

"Se é só essa a ajuda que você pode me dar, eu dispenso... pode me deixar aqui sozinha que eu sei o que é melhor pra mim e pro meu filho"

[Tudo que eu precisava nessa hora era acolhimento, era incentivo, era alguém pra me falar que estava tudo bem e que tudo daria certo, não alguém me dizendo q meu filho cairia no chão. Fui muito grossa com a enfermeira nessa hora e não me arrependo.]

Ela sai da sala e eu fico sozinha de novo.

Entra o obstetra plantonista 
"Eu preciso que você deite na maca porque não vai dar tempo do teu medico chegar então eu vou fazer o teu parto"

"Eu já falei que não vou deitar e eu não preciso que você faça o meu parto, eu sei o que fazer e farei sozinha" [Essa frase "fulano fez meu parto" sempre me incomodou. Em condições normais o médico não faz nada, quem faz todo o trabalho é a mulher.]

Ele não ficou muito contente, mas não insistiu. Sentou e ficou só me olhando. Tive outra contração forte e gritei algo como "aaiii, me ajude"... o obstetra falou "ué, você não disse que sabia o que fazer e faria sozinha?"

Passada a dor, me vi sozinha novamente na sala.

Comecei a sentir uma vontade imensa de empurrar, de fazer força. Incontrolável. A dor sumiu totalmente, só sentia uma pressão no assoalho pélvico e minha barriga baixou assustadoramente. Saiu o tampão mucoso, bem maior e mais cheio de sangue do que eu imaginava. A cada contração eu empurrava e sentia a cabecinha coroando e voltando.

"Vai nascer, chama meu marido!!!"

Entraram o médico e as enfermeiras novamente.

"Moça, é sério, você não pode ter esse bebê aí no chão, eu vou te ajudar a subir na maca, não precisa deitar se não quiser, mas suba na maca!"

“ok, mas eu não vou deitar..."

Nessa hora lembro que olhei bem pra cara do médico e disse:

"Doutor, eu não quero episio, de jeito nenhum!"

"Tudo bem, mas suba na maca"

[Episiotomia é o corte feito no períneo para supostamente facilitar a saída do bebê. As evidências cientificas mostram que nenhuma episio é necessária, porque não ajuda em nada, não previne laceração já que é pior que uma laceração. Episiotomia é crueldade, é mutilação genital. Porém, a maioria dos médicos a faz sem ao menos consultar a parturiente.]

Subi na maca e fiquei de cócoras. Pedi pra chamarem o Julio. Me deixaram sozinha de novo.

Eu sentia a cabecinha coroando e voltando. O Julio chegou e se assustou por eu estar sozinha, não entendeu nada. Ele esperava algo parecido com a cesárea, esperava que ia assistir e não participar. Eu não consegui explicar nada do que eu tinha passado, só disse pra ele ficar ali comigo, e ele ficou. Na próxima contração o bebê coroou. 
[É impressionante o controle que a gente tem do períneo, coisa que eu nem sonhava. Eu estava "segurando" o bebê já há algumas contrações, quando me vi segura, relaxei o períneo para que ele coroasse. Se eu estivesse anestesiada não teria esse controle]

Pedi pro Julio olhar:

"Julio, olhe lá, saiu a cabecinha..."

"Meu Deus, saiu a cabeça, o que que eu faço, vou chamar alguém!!!"

"Não, calma, tá tudo certo, é assim mesmo, não chama ninguém. Pega aquele pano e se prepara porque na próxima contração vai sair o bebê inteirinho e você precisa segurar."

"Mas não é melhor eu chamar o médico, e se acontecer alguma coisa?"

"A única coisa q vai acontecer agora é esse bebê nascer! Se prepara que é agoraaa..."

Veio a contração, sem dor nenhuma, só a vontade de empurrar. Senti o Otto saindo inteirinho de dentro de mim. Um alivio indescritível. Uma sensação de poder, de domínio do meu corpo, coisa que eu jamais havia sentido antes. Eu só pensava que se eu fiz isso, eu faço qualquer coisa!

O Julio pegou o Otto, enrolou no pano e me deu. Encolhidinho, chorou forte, alto. Eu estava em êxtase.

"Agora eu vou chamar um médico, Vanessa..."

"HAHAHA, agora você pode chamar quem você quiser!"

Entraram todos, obstetra plantonista, enfermeiras, pediatra...

Pedi pra ficar com o bebê por um tempo, eu queria dar o peito antes de levarem ele para os exames. O pediatra concordou. Sugeriu que eu tirasse a roupa e colocasse o bebê em contato com a minha pele e assim tentasse amamentar. Fiquei com ele um bom tempo assim.

[As evidências mostram que amamentar o bebê na primeira hora de vida, assim como colocá-lo diretamente na pele, favorece a descida do leite e a criação de vínculo entre a mãe e o bebê.]

O obstetra disse que precisava tracionar a minha placenta, que ainda não havia "nascido". Eu neguei.

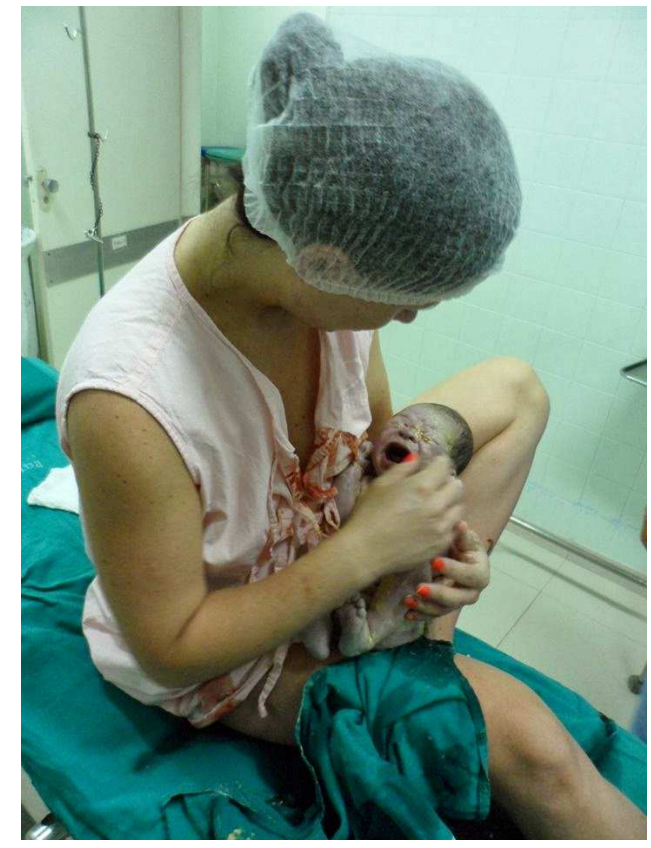

"Eu queria esperar ela sair naturalmente, com as contrações"

"É que as vezes ela não sai sozinha e é preciso dar uma puxada" 
"Vamos esperar pelo menos mais uma contração então"

"Mas não tem porque esperar..."

Eu estava cansada demais pra continuar aquela discussão, por sorte o pediatra que estava na sala ouviu e interferiu:

"Doutor, faz o que ela tá pedindo, não custa..."

A contra gosto ele esperou e a placenta saiu inteira na primeira contração.

Não satisfeito, ele queria cortar o cordão desesperadamente. Eu pedi pra esperar parar de pulsar. Ele argumentou. O pediatra novamente interferiu.

"Dá pra esperar sim, vamos esperar"

[Enquanto o cordão está pulsando, o sangue da placenta está indo para o bebê, o que previne a anemia no recém nascido.]

Depois de cortado o cordão, fiquei ainda alguns minutos com o Otto nos braços, amamentando.

Pouco antes de levarem ele para pesar e examinar, chegou o meu obstetra, esbaforido e se desculpando. Não havia do que se desculpar, nem nos meus melhores sonhos eu imaginaria que meu trabalho de parto fosse ser tão rápido. Ele demorou cerca de meia hora, mas já era tarde. Ele me examinou para ver se não havia laceração. Nada. Uma pequena escoriação, mas que não seria preciso nenhum ponto. O Julio foi com o pediatra acompanhar os procedimentos no bebê e depois nos encontramos no quarto.

O Otto nasceu às $6 \mathrm{~h}$ da manhã do dia 30/01/14, com $3750 \mathrm{~g}$ e $52 \mathrm{~cm}$, de 41 semanas e 5 dias de gestação, depois de 4 horas de trabalho de parto sem nenhuma intervenção médica, aparado pelo pai em um parto natural hospitalar desassistido."

Mais longo e detalhado que os relatos anteriores, o relato de Vanessa impressiona pelo desenvolver da história e por sabermos que o tratamento direcionado à ela não é diferente para muitas parturientes: ordens, imposições, violência verbal e violência psicológica. Vanessa, como explica durante a narrativa, é acompanhada pelo Dr. Álvaro - Álvaro Silveira Neto, ginecologista e obstetra curitibano, apoiador de partos naturais humanizados -, porém o seu parto não fora acompanhado por seu médico, pois contra-tempos acontecem e ele não chegou no momento exato 
para auxiliá-la. Vanessa foi atendida pelo obstetra plantonista, que com sua boa formação tecnocrática de medicina, a reduziu à uma máquina de parir que precisava ser operada.

Vanessa sabia muito bem sobre o que queria e como queria e em seu relato fica evidente que sua participação nas decisões de seu parto incomodou e muito a equipe médica de plantão. Também durante a narrativa ela explica termos e por quês das suas decisões o que mostra seu conhecimento sobre o assunto e sua postura firme e confiante. Mas a violência por qual passou, tanto verbal quanto psicológica, foi uma adversidade com que ela teve que enfrentar com determinação, pois se esmorecesse sabia que a violência passaria para o nível físico e atos mais invasivos poderiam acontecer como a episiotomia (que ela falou que não queria), introdução de ocitocina (também negada por ela), uso de fórceps e outros instrumentos.

Depois de ser deixada sozinha na sala, Vanessa relata que começara a sentir Otto descer e subir, na tentativa de coroar, mas foi só seu marido Julio chegar para que ela se sentisse segura e confiante a ponto de permitir Otto a vir, o que ela chamou de 'controle de períneo'. Poucas contrações depois, Otto estava nas mãos do pai esperando para conhecer também sua mãe. Todos os sentimentos vividos por Vanessa influenciavam em seu trabalho de parto e o mesmo acontece com a maioria das mulheres. Quando estava tensa, seu corpo segurava o andamento do nascer, quando estava com medo, a dor a submetia a instantes terríveis, quando se sentiu protegida, seu corpo se soltou, a dor sumiu e seu filho pôde finalmente nascer.

Com o exemplo de Vanessa é possível compreender duas posturas de parturiente extremamente opostas e que sustentam a dicotomia parto humanizado/parto tecnocrático: mulheres que se preparam para a dor, que estudam o parto como prática, que conhecem seu corpo, sentem seu bebê, que querem participar ativamente do nascimento do seu filho, que querem respeitar o seu organismo e tempo e sentir o seu filho o máximo possível durante seu nascer, são as mulheres que buscam no parto natural humanizado o apoio necessário para fazer do sonho uma realidade. Do outro lado da moeda, fazendo parte da grande engrenagem de um sistema de comércio, está a mulher de postura passiva, que vê no médico e em sua equipe as pessoas certas para fazer seu parto, que não quer sentir dor, que quer "dormir e acordar com o filho nos braços", que paga pelo valor que dizem ser o justo para essa operação.

A última postura retratada pode ser adotada devido a várias induções. Primeiro, por estar cristalizado na consciência coletiva que parto é aquilo que a imagem de uma mulher deitada numa maca, vestida de azul, ladeada por médicos representa. Segundo, por não se acreditar que as mulheres sejam capazes de parir sem intervenção médica. Terceiro, por muitas mulheres terem 
medo da dor e preferirem partos que a poupem desse incômodo. Porém, os números de cesarianas no mundo, e principalmente no Brasil, estão alarmantes. Segundo a jornalista Valéria Perasso da rede $\mathrm{BBC}$ Brasil:

\begin{abstract}
Atualmente, mais da metade dos bebês brasileiros nascem desta forma [cesariana] - um índice que chega a $84,6 \%$ na rede particular -, segundo a Organização Mundial da Saúde (OMS). O órgão recomenda que a taxa fique entre $10 \%$ e $15 \%$ dos partos. A cirurgia é cada vez mais simples e segura e pode ser necessária para salvar gestante e bebê quando é identificado riscos na realização do parto normal. Mas a cirurgia ainda implica em perigos, e o número de cesarianas feitas por opção da mãe, sem recomendação médica, vem aumentando. (PERASSO, 2015) ${ }^{8}$
\end{abstract}

O que classifica a atualidade como uma 'epidemia de cesarianas' como a própria jornalista usa em seu título de matéria. Esse quadro é de grande impacto, pois as questões que envolvem o parto, depois que esse ocorre, são substituídas por questões referentes ao pós-parto, à recuperação da mãe, ao envolvimento mãe-bebê e outras consequências que resultam da inicial escolha de qual parto será.

\title{
CONSIDERAÇÕES FINAIS
}

Ao estudar a temática 'partos' nós somos projetados para além de um mundo de pura medicina. Adentramos em questões históricas, em questões culturais, em questões sociais, financeiras, em ideias de mística, de espiritualidade, de força, de poder, de conhecimento, de renovação. Muitas vezes em que queremos representar um novo começo, utilizamos da ideia do nascer. Um novo ano nasce, uma nova etapa nasce, um novo ciclo nasce, e o nascimento, seja de seres vivos seja de momentos que trilhamos, é uma oportunidade de renovação, de fazer diferente, fazer melhor. Porém, quando queremos nos referir a algo complicado, difícil, penoso, dizemos "nossa! Foi um parto aquilo". Michel Odent, obstetra francês, disse certa vez uma frase que se tornou referência para o trabalho de humanização do parto: "Para mudar o mundo, primeiro é preciso mudar a forma de nascer". Precisamos sair desse ciclo vicioso de partos desrespeitados, violentados, de mães humilhadas e crianças ignoradas, para podermos experimentar um mundo melhor.

\footnotetext{
${ }^{8}$ Dado disponível em http://www.bbc.com/portuguese/noticias/2015/07/150719_cesarianas_mundo_rb. Acessado 23 de Janeiro de 2016.
} 
O parto natural humanizado é uma tentativa de fazer a mulher assumir novamente seu posto de geradora capaz e com total poder de trazer seu fruto ao mundo, é uma tentativa de mostrar que é possível mesmo com adversidades superar medos e inseguranças, é uma tentativa de criar vínculos realmente fortes entre aqueles que presenciam o nascer, é uma tentativa de fazer diferente, fazer melhor. O parto natural humanizado nasceu para calar o oportunismo e elevar as grandes experiências da vida.

\section{REFERÊNCIAS}

PACIORNIK, Moysés. Aprenda a viver com os índios: o parto de cócoras, desempenho sexual, ginástica índia, comer e descomer. Rio de Janeiro - Ed. Espaço e Tempo. 1987.

JONES, Ricardo. Memórias de um homem de vidro: reminiscências de um obstetra humanista. 3ed - Porto Alegre: Ideias a Granel. 2012.

CARNEIRO, RosamariaGiatti. Cenas de Parto e Políticas de Corpo: uma etnografia de práticas femininas de parto humanizado. Tese Doutorado em Ciências Sociais. Campinas. São Paulo [s.n], 2011.

DUTRA, Ivete Lourdes. Parto natural, normal e humanizado: a polissemia dos termos e seus efeitos sobre a atenção ao parto. Dissertação Mestrado em Enfermagem. Porto Alegre, 2005.

On-line:

Nascer com Respeito: http://nascercomrespeito.com.br/equipe/ . Acessado 15 de novembro 2015.

Gazeta do Povo: http://www.gazetadopovo.com.br/vida-e-cidadania/banheira-dagua-e-alternativade-parto-natural-cmr5n8j8ovz8mawnleahrntce. Acessado 15 de Novembro de 2015.

Diário de uma Doula: http://diariodeumadoula.blogspot.com.br/2014/05/parto-humanizado-emcuritiba.html. Acessado 15 de Novembro de 2015.

Prefeitura de Curitiba: http://www.curitiba.pr.gov.br/noticias/indice-de-partos-normais-no-sus-decuritiba-e-seis-vezes-maior-que-na-rede-particular/35110 . Acessado 15 de Novembro de 2015.

Prefeitura de Curitiba: http://www.feaes.curitiba.pr.gov.br/index.php/noticias/ultimas-noticias/442instituto-da-mulher-sera-referencia-nacional-em-parto-humanizado . Acessado a 15 de Novembro de 2015.

Doula Curitiba: http://www.doulacuritiba.com.br/. Acessado 15 de Novembro de 2015.

Centro de Parto Ativo: http://www.centrodepartoativo.com.br/inicial.php. Acessado 15 de Novembro de 2015. 
MaterGaia: http://www.matergaiacuritiba.blogspot.com.br/. Acessado 15 de Novembro de 2015.

Casa Mãe: https://casamae.wordpress.com/. Acessado 15 de Novembro de 2015.

Movimento Bem Nascer: https://bemnascercuritiba.wordpress.com/. Acessado 15 de Novembro de 2015.

Maternarum: http://maternarum.com.br/. Acessado 15 de Novembro de 2015.

Mãezíssima: http://www.maezissima.com.br/. Acessado 15 de Novembro de 2015.

EGO Rio: //ego.globo.com/gravidez/noticia/2015/05/quiteria-chagas-da-luz-em-casa-e-defendeparto-humanizado-radiantes.html. Acessado 15 de Novembro de 2015.

Facebook - O Renascimento do Parto: https://www.facebook.com/orenascimentodoparto/photos. Acessado a 25 de novembro de 2015.

Enquanto vocês cresciam: http://enquantovocescresciam.blogspot.com.br/. Acessado 21 de Janeiro de 2016.

BBC Brasil: http://www.bbc.com/portuguese/noticias/2015/07/150719_cesarianas_mundo_rb. Acessado 23 de Janeiro de 2016.

\section{WOMAN, BODY AND LIFE: BACKGROUND ON THE BIRTH HUMANIZED IN CURITIBA CITY}

\footnotetext{
Abstract

Addressing the theme of humanization of childbirth, this paper aims to assist in the dissemination of information regarding the history of childbirth, childbirth models and especially the awareness of the practice of humanized natural birth. For its preparation had been used as Paciornik authors (1987), Dutra (2005), Jones (2012), Davis-Floyd (2012) and Carneiro (2011), as well as reports of women exposed on web sites and social networks. With the search you can check the change of thought and speech that is happening with the people who come in contact with the subject and deepen their research. The humanized natural childbirth is a theme in vogue and that needs visibility and attention.
}

Key-words: Birth. Humanization. Woman. Empowerment. Ideology 